\title{
SEISMICITY CHARACTERISTICS IN SHIKOKU IN RELATION TO THE GREAT NANKAIDO EARTHQUAKES
}

\author{
Kennosuke OKano* and Shozo KimUra** \\ *Department of Physics, Faculty of Science, Kochi University, Kochi, Japan \\ **Kochi Earthquake Observatory, Faculty of Science, Kochi University, \\ Kochi, Japan
}

(Received February 9, 1979)

\begin{abstract}
Earthquakes occurring in Shikoku are distinctly divided into two groups according to whether their focal depths are above or below a depth of about $20 \mathrm{~km}$. The shallower earthquakes have pressure axes in the E-W direction and the deeper ones in the N-S direction. On the other hand, it is well known that the 1946 great Nankaido earthquake was followed by many aftershocks having pressure axes in the E-W direction, and that most of earthquakes which occurred before the great earthquake had pressure axes in the N-S direction. This abrupt change of pressure systems may be reasonably explained by considering that the activity of the shallower earthquakes has become more predominant than that of the deeper ones since the occurrence of the 1946 Nankaido earthquake. The predominance is considered to be a reflection of the decrease of stress in the N-S direction which had acted on the upper crust owing to the elastic rebound accompanying the great earthquake. The seismological data of the Japan Meteorological Agency suggest that the seismic activity in Shikoku was significantly low for several years before the 1946 earthquake. The Kochi Earthquake Observatory has observed gradual decaying of activity of the shallower earthquakes since 1967. Accordingly, it can be presumably expected from these observations that the activity of the shallower earthquakes will become lower than usual just before a future Nankaido earthquake.
\end{abstract}

\section{Introduction}

Two seismically active regions with different depths were found in the Shikoku district from the observations of the Kochi Earthquake Observatory (SAWAMURA and KIMURA, 1971). The shallower (less than about $20 \mathrm{~km}$ ) and deeper (greater than about $20 \mathrm{~km}$ ) earthquakes have pressure axes in the E-W and N-S directions, respectively. On the other hand, it is reported by ICHIKAWA (1965) that the pressure system of shallow events in the east part of Shikoku abruptly changed in the time after the 


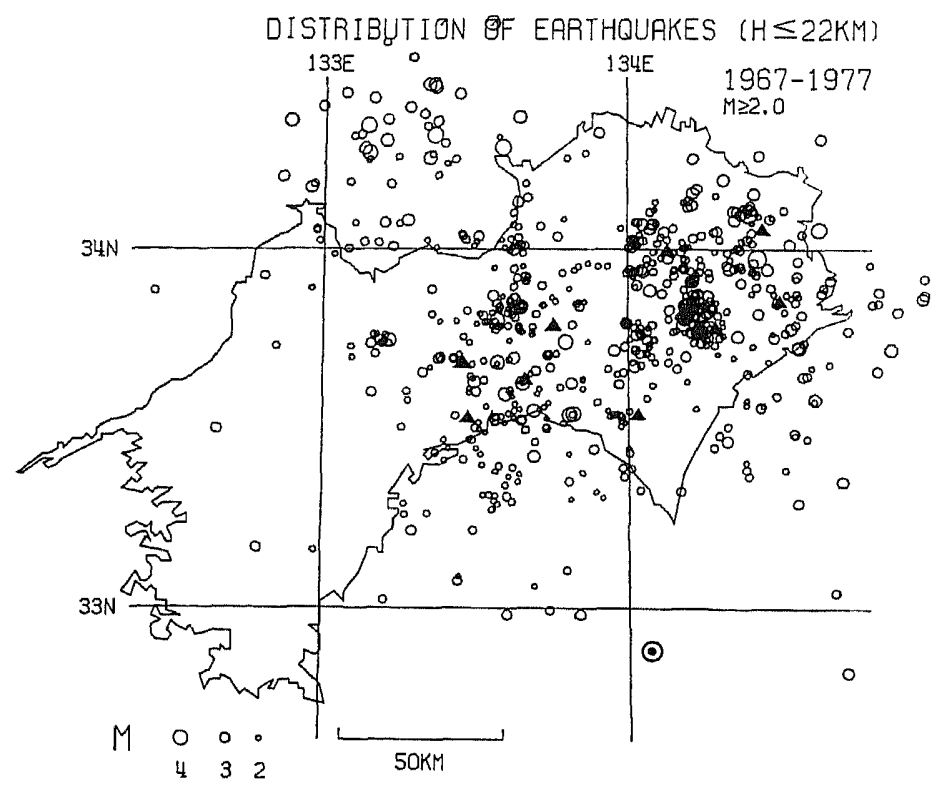

Fig. 1. Epicentral distribution of the shallower earthquakes $(h \leqq 22 \mathrm{~km})$ with magnitudes of 2.0 and greater for 1967 to 1977 . The symbol $\odot$ shows the epicenter of the 1854 Ansei Nankaido earthquake as located by Omori. Closed triangles show observation stations.

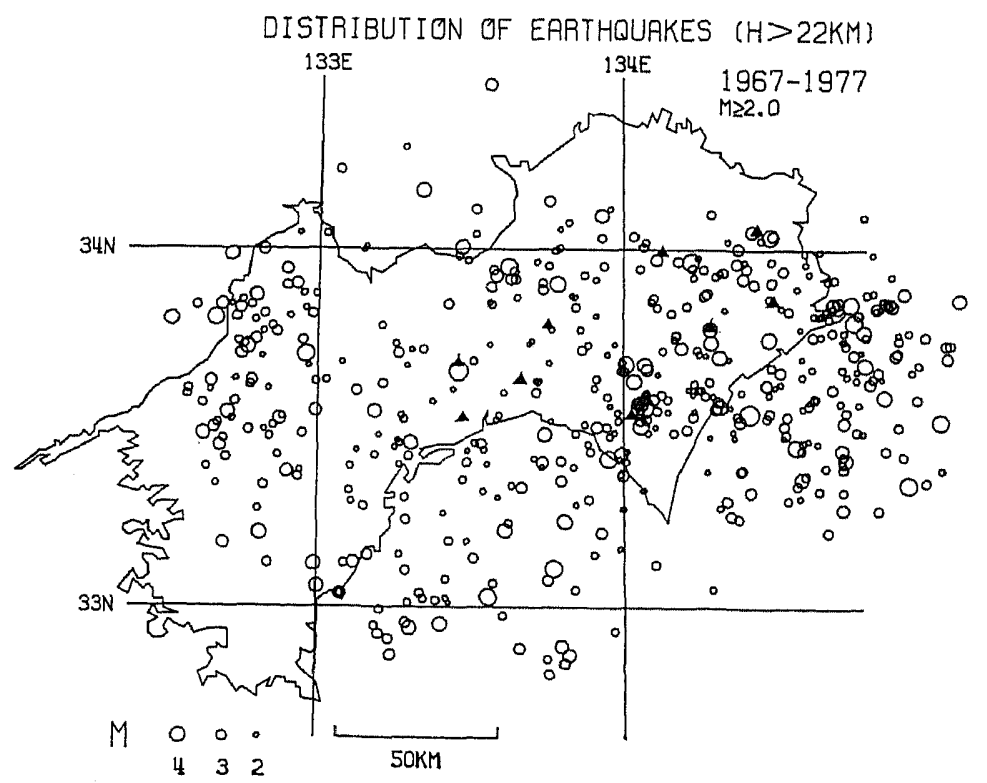

Fig. 2. Epicentral distribution of the deeper earthquakes ( $h>22 \mathrm{~km}$ ) with magnitudes of 2.0 and greater, for 1967 to 1977. Symbols are same as in Fig. 1. 
great Tonankai and Nankaido earthquakes occurring in 1944 and 1946 respectively. This paper suggests that these observations are not contradictory but rather closely related with one another.

\section{General Views of Seismicity in Shikoku}

Figures 1 and 2 show the epicentral distributions of earthquakes of shallower than $22 \mathrm{~km}$ and deeper than $22 \mathrm{~km}$, respectively for the period of 1967 to 1977 . Figures 3 and 4 show the hypocentral distributions of

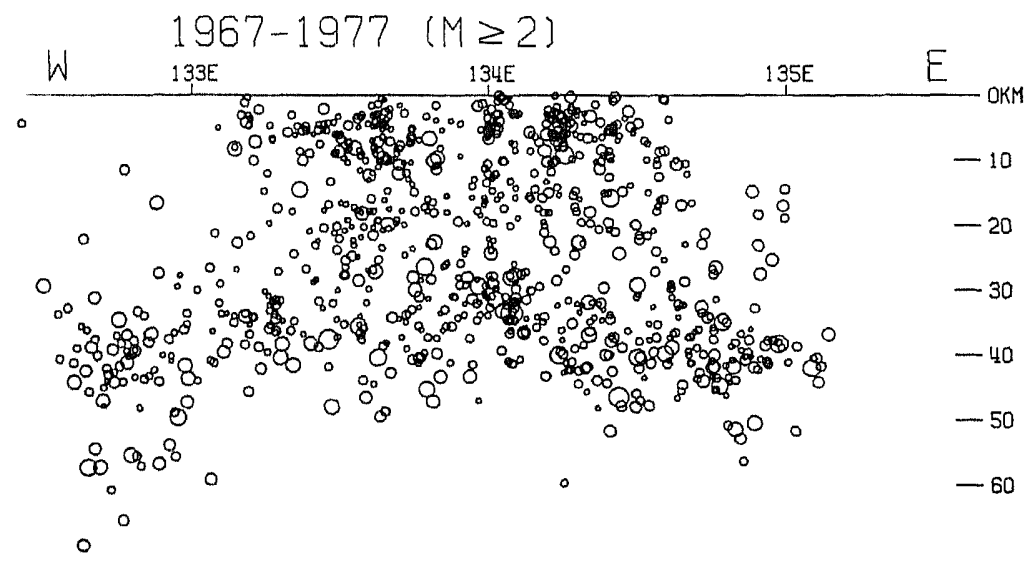

Fig. 3. Focal depth distribution of earthquakes for a vertical section in the E-W direction for 1967 to $1977(M \geqq 2.0)$.

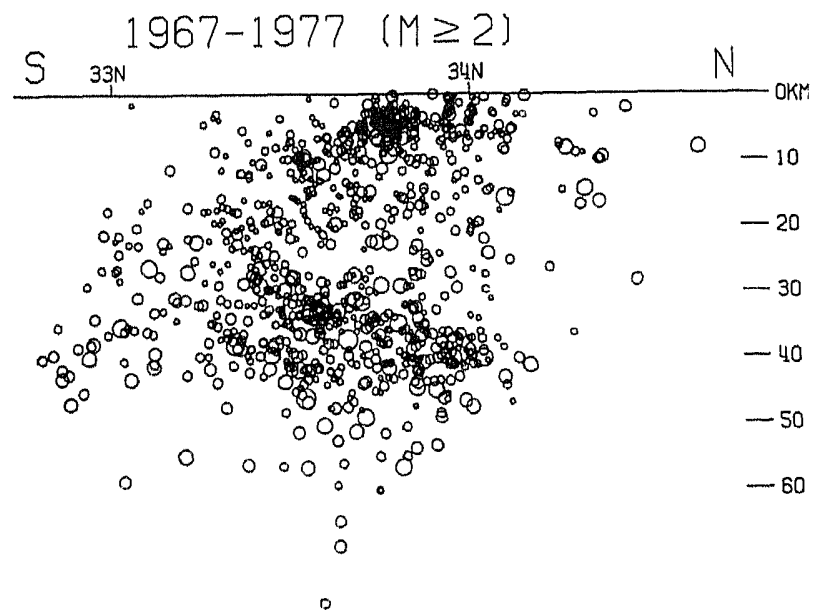

Fig. 4. Focal depth distribution of earthquakes for a vertical section in the N-S direction for 1967 to $1977(M \geqq 2.0)$. 


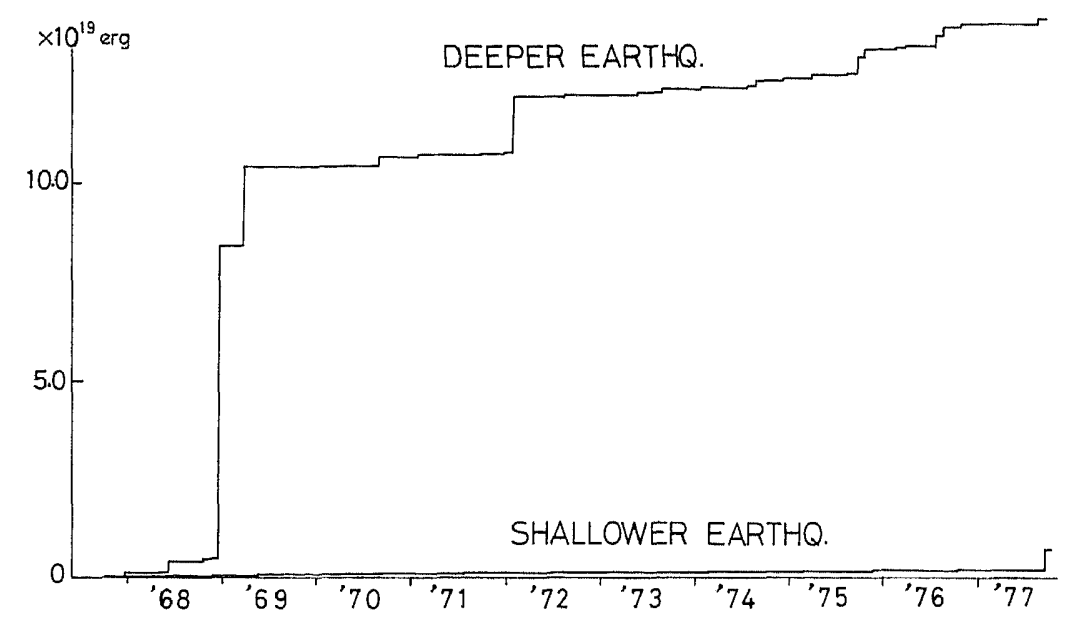

Fig. 5. Energy release diagrams for the shallower and deeper earthquakes.

vertical sections in the $E-W$ and N-S directions, respectively for the same period. The shallower earthquakes seldom occur in the west part, moderately in the central and most frequently in the east, as shown in Fig. 1. The deeper earthquakes occur uniformly all over the Shikoku district, as shown in Fig. 2. As the deeper earthquakes are greater in magnitude than the shallower ones, earthquake energy released by the former is far greater than by the latter as shown in Fig. 5. Accordingly, the deeper earthquakes must play the leading seismic role in Shikoku.

\section{Change of Pressure Axes of Earthquakes Observed before and after the 1946 Nankaido Earthquake}

Figure 6 shows a temporal variation of earthquake occurrence in Shikoku since 1928. This figure was made using data from the ICHIKAWA's paper (1965), the Seismological Bulletin published by JMA and the Report of the Kochi Earthquake Observatory for the periods of 1928 to 1959, 1960 to 1966 and 1967 to 1977. Bars drawn upwards and downwards correspond to the earthquakes with pressure axes in the E-W and $\mathrm{N}-\mathrm{S}$ directions, respectively. In Fig. 6 small events of magnitudes less than 4.0 are excluded because of ambiguity of fault plane solutions. Although the data used, especially those obtained in the early period, are not necessarily adequate to the present study because of insufficient seismometric magnification, a change of pressure systems is clearly seen before and after the Nankaido earthquake. This change of pressure systems has been generally accepted to be due to the change in direction of stress acting on the upper crust. 


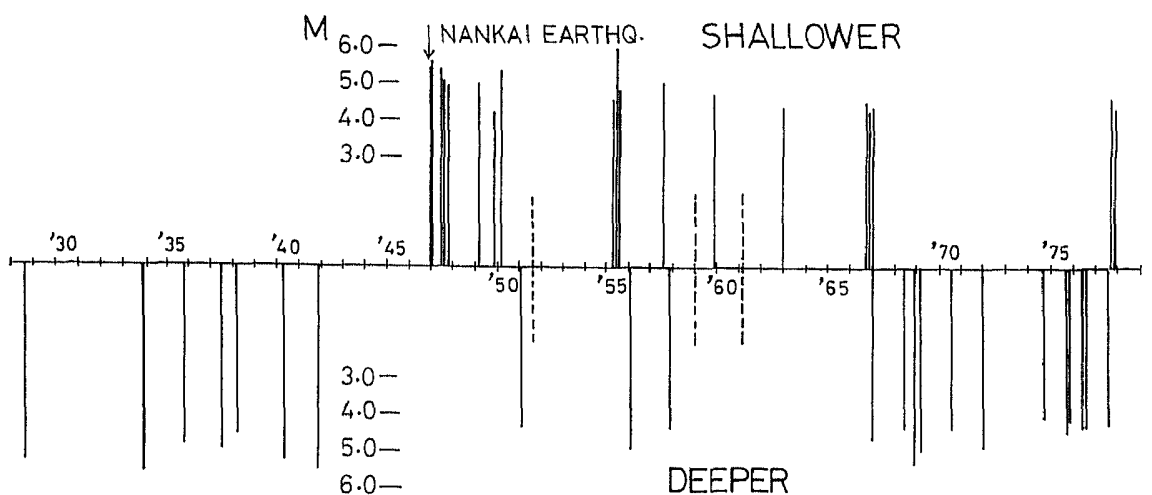

Fig. 6. Variation of earthquake occurrence arranged separately according to the direction of pressure axes. Bars drawn upwards and downwards correspond to the earthquakes with pressure axes in E-W and N-S directions, respectively. Dotted bars show earthquakes $(M>4.0)$ with indeterminable axis directions.

Nevertheless, we prefer to regard the change as only apparent. The apparent change is not caused by the change of pressure systems but by predominance of the seismic activity of the shallower zone rather than the deeper zone. Most of the aftershocks accompanying the Nankaido earthquake occurred in the upper crust, whereas few earthquakes with significantly large magnitudes had occurred in the upper crust before 1946. In consequence, the apparent change of pressure systems was merely observed before and after the Nankaido earthquake. A reason why the aftershocks predominantly occurred in the upper crust in Shikoku can now be elucidated. The great Nankaido earthquakes have frequently occurred along the Nankai Trough in history. The stress in the N-S direction generating these great earthquakes is considered to be due to underthrusting in southwest Japan (Sawamura, 1953; Fitch and Scholtz, 1971). This stress acts also on the subcrust and/or on the uppermost mantle in Shikoku and causes the deeper earthquakes mentioned in section 2. When a great Nankaido earthquake occurs along the Nankai Trough, the upper crust elastically rebounds upwards and southwards, and releases a part of the accumulated stress. As is well known, the elastic rebound is testified by the uplift of the Muroto and Ashizuri Points following the great earthquakes. The release of stress in the N-S direction causes relative increase of the stress in the $\mathrm{E}-\mathrm{W}$ direction and, as a consequence, aftershocks with the E-W pressure axes occur mainly in the upper crust.

\section{Temporal Variation of the Seismic Activity in Shikoku}

We examined the temporal variation of seismic activity using the 
yearly variation of frequency-magnitude relation, but no conclusive results were obtained (OKANo et al., 1978). Accordingly, in this study, we decided to examine the yearly variation of the cumulative number for earthquakes greater than a certain magnitude. Figures $7(a)$ and (b) show the variations corresponding to the shallower and the deeper earthquakes, respectively. Beginning with three stations in April of 1967, our observations have been improved, in detectability and on locating, by the installation of more two observation stations in April of 1972. Hence, owing to the improvement of detectability, a greater number of earthquakes of small magnitudes were located in the latter period than in the early period. The detectability of large earthquakes is not so seriously affected by the

(a)
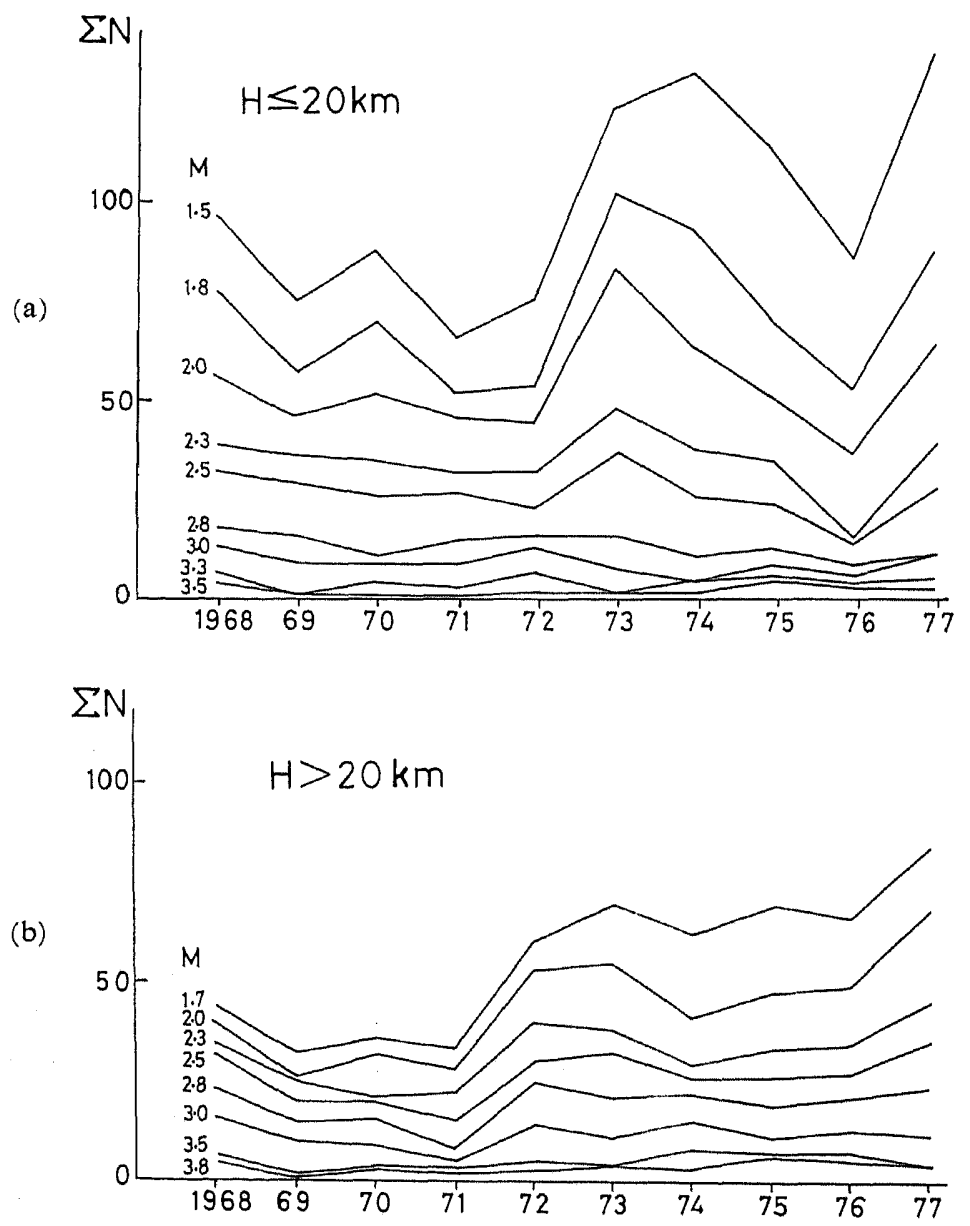

Fig. 7. Yearly variation of seismic activities, (a) for the shallower and (b) for the deeper earthquakes. 
number of stations as that of small earthquakes. Now, as seen in Fig. 7 (a), the activity of the shallower earthquakes with magnitudes of 2.8 and greater has a tendency to decay throughout the whole period. The decay of activity can be recognized also for earthquakes of smaller magnitudes, by careful and individual inspection of the variations of the earlier and later periods. However, such a tendency is not recognized for the deeper earthquakes, as is shown in Fig. 7(b).

\section{Seismic Activity before and after the 1946 Nankaido Earthquake}

If the activity of the shallower earthquakes continues to decay gradually, the seismic activity should become extremely low for a while just before occurrence of a forthcoming Nankaido earthquake. Based on this supposition, we would expect that there was a period of such a low activity also just before the 1946 Nankaido earthquake. It is, therefore, interesting to examine in detail how seismicity varied with time just before the 1946 earthquake. Fortunately, earthquake intensities in Kochi City have been determined and seismometric observations had been carried out by JMA since 1926 by means of the Wiechert seismograph, with magnification of about 50. The lower graph in Fig. 8 shows yearly numbers of earthquakes felt in Kochi City. This graph is not adequate to distinguish the characteristics with which we are concerned here, because earthquakes which occurred in the outer districts of Shikoku are included

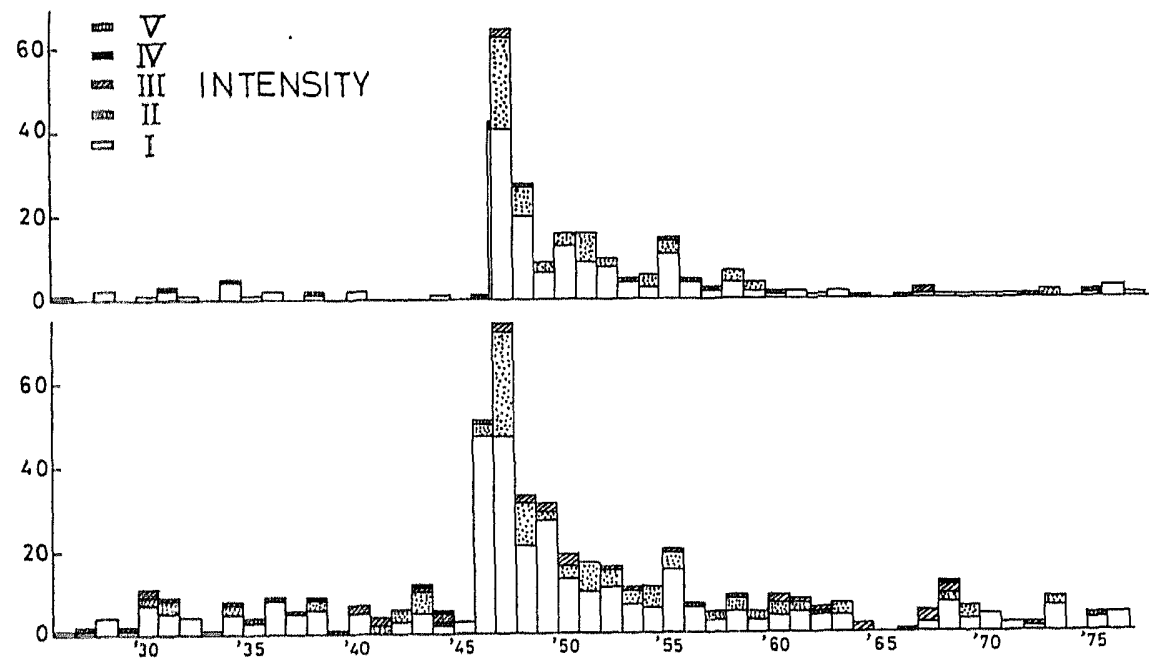

Fig. 8. Yearly numbers of felt earthquakes in Kochi City observed by JMA. The upper part is for the earthquakes whose epicenters are in the Shikoku district and the lower part is for all felt earthquakes. 
in large numbers. Therefore, the upper graph is drawn from the lower one, after excluding such earthquakes, in order to examine the earthquakes occurring in Shikoku only. Unfortunately, it is difficult to confirm the above inference based on the data of the shallower earthquakes alone, because of difficulty of separating earthquakes with different depths into the two earthquake groups. Nevertheless, a low seismic activity is clearly seen for several years before 1946 compared with the other periods. Furthermore, the earthquake of intensity I of 1944 in the upper graph should be excluded from this graph, because this event has such a relatively small magnitude judging from P-S time of $0.8 \mathrm{sec}$ observed by the Kochi Local Meteorological Observatory of JMA. To sum up, the very low seismic activity becomes a reasonable assumption.

\section{Main Aftershock Region}

As pointed in section 2, the epicentral distribution of the shallower earthquakes shown in Fig. 1 is divided into three parts; east, central and west. The east part is most seismically active of the three, the central part is moderately seismic and the west part nearly aseismic. Moreover, since earthquakes with larger magnitudes most predominantly occur in the east part, this part may possibly be regarded as the main aftershock region of the 1946 (Showa) Nankaido earthquake. The central part does not have as high seismicity as the east part. On the other hand, aftershocks of the 1854 (Ansei) Nankaido earthquake were more active in the central part than in the east according to UsAMI (1975). Accordingly, it may be supposed that the central part corresponds to the main aftershock region of the Ansei earthquake. The most likely location of the epicenter of the great earthquake is considered to be the one given by Omori, which is plotted in Fig. 1. It is probable that the 1854 Ansei tsunami was about 1.3 times as large in height as the 1946 Showa tsunami along the Tokushima coast, and about 2 times along the Kochi coast (HATORI, 1978).

\section{Conclusions}

It is well known that the pressure systems in Shikoku abruptly changed after the 1946 Nankaido earthquake. The abrupt change is not caused by a change of pressure system itself but should be explained by the transition of the seismically active zone from the deeper to the shallower zones where pressure systems are different from each other. It is presumed that the seismicity of the shallower earthquakes becomes extremely low than usual just before an occurrence of a forthcoming great Nankaido earth- 
quake, based on the data presented in this paper, for instance, decreasing of the activity of the shallower earthquakes observed by the Kochi Earthquake Observatory and the low seismic activity for several years before 1946 in Shikoku observed by the Kochi Local Meteorological Observatory of JMA. Next, we suggest that the seismic activities in the east and central parts of Shikoku represent the respective aftershock activities of the 1946 and 1854 great Nankaido earthquakes. Aseismicity in the western part is a problem for further discussion.

We are very greatful to the Kochi Local Meteorological Observatory of the Japan Meteorological Agency for providing the seismological data. We wish to express our gratitude to Mr. Isamu Hirano of the Regional Observation Center for Earthquake Prediction of the Kyoto University for critically reviewing this manuscript. Great acknowledgment is made to Mr. Kazuo Kawatani of the Kochi Earthquake Observatory for assistance in observations. Computations and drawing of earthquake distributions were carried out on the Facom 270-30 system of the Computer Center of the Kochi University.

\section{REFERENCES}

I'HIKAwa, M., The mechanism of earthquakes occurring in central and southwest Japan and some related problems, Pap. Met. Geophys., 16, 104-156, 1965.

Firch, T. J. and C. H. ScholTz, Mechanism of underthrusting in Southwest Japan: a model of convergent plate interactions, J. Geophys. Res., 76, 7260-7292, 1971.

HA TORI, T., Monuments of the Nankaido tsunamis of 1605, 1707 and 1854 in the Shikoku District: Behavior of historical tsunamis and their comparison with the 1946 Nankaido tsunami, Bull. Earthq. Res. Inst., 53, 423-445, 1978 (in Japanese).

OKANO, K., S. Kimura, and T. Konomi, Seismic activity in the central and eastern part of Shikoku district, Zishin (J. Seismol. Soc. Japan), 31, 63-72, 1978 (in Japanese).

SAwamura, $T$., Relation between the activities of the outer earthquake zone in southwestern Japan and the geologic structure and crustal movements of Shikoku and its vicinity, Res. Rep. Kochi Univ., 2, 1-46, 1953 (in Japanese).

SAwamura, T. and S. Kimura, Activities of micro-earthquakes in central Shikoku (II), Res. Rep. Kochi Univ., 20, Natural Science No. 14, 241-249, 1971 (in Japanese).

Usımi, T., Aftershock activity of the Nankai earthquake of December 24, 1854-.-Decrease of aftershock activity of some historical earthquakes, Bull. Earthq. Res. Inst., 50, 153169, 1975 (in Japanese). 